\title{
Incorporation of essential oils in Iranian traditional animal oil: an assessment of physicochemical
}

\section{and sensory assessment}

\author{
Maliheh Azizi ${ }^{1}$, Fatemeh Fazeli ${ }^{1 *}$, Mehrdad Mohammadii", Amin Mousavi Khaneghah ${ }^{3 *}$ \\ ${ }^{1}$ Department of Food Science and Technology, Ayatollah Amoli Branch, Islamic Azad University, Amol, Iran; ${ }^{2}$ Department \\ of Food Technology Research, National Nutrition and Food Technology Research Institute, Faculty of Nutrition Sciences \\ and Food Technology, Shahid Beheshti University of Medical Sciences, Tehran, Iran; ${ }^{3}$ Department of Food Science and \\ Nutrition, Faculty of Food Engineering, University of Campinas (UNICAMP), Campinas, São Paulo, Brazil
}

"Corresponding Authors: Fatemeh Fazeli, Department of Food Science and Technology, Ayatollah Amoli Branch, Islamic Azad University, Amol, Iran. Email: fatemeh_fazeli2002@yahoo.com; Mehrdad Mohammadi, Department of Food Technology Research, National Nutrition and Food Technology Research Institute, Faculty of Nutrition Sciences and Food Technology, Shahid Beheshti University of Medical Sciences, Tehran, Iran. Email: mohammadi@sbmu.ac.ir; Amin Mousavi Khaneghah, Department of Food Science and Nutrition, Faculty of Food Engineering, University of Campinas (UNICAMP), Campinas, São Paulo, Brazil. Email: mousavi@unicamp.br

Submitted: 10 March 2021; Accepted: 5 May 2021; Published: 29 June 2021

(c) 2021 Codon Publications

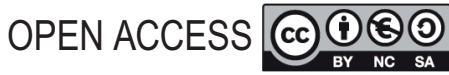

PAPER

\section{Abstract}

This study aimed to incorporate the herbal essential oils (Ziziphora tenuior L. (Z. tenuior), Ferulago angulata ( $F$. angulata), and Bunium persicum (B. persicum)) all in three levels (5, 7, and $10 \% \mathrm{w} / \mathrm{w}$ ) and tertiary butyl hydroquinone $(100,200$, and $300 \mathrm{ppm})$ to evaluate the oxidation stability of Iranian animal oil (IAO). Z. tenuior, F. angulata, and B. persicum (5, 7, and 10\% w/w) and tertiary butyl hydroquinone (100, 200, and $300 \mathrm{ppm})$ were added to IAO. The physicochemical properties and color analysis, and sensory characteristics (odor, taste, rancidity, and overall acceptability) of the treatments were investigated on days $0,7,14,21$, and 28 . The results showed that increasing the amounts of $Z$. tenuior, $F$. angulata, and B. persicum was associated with reducing acid, peroxide, and thiobarbituric acid values. It also lowered brightness and yellowness while the oxidative stability of the IAO significantly was increasing. It was concluded that the incorporation of B. persicum had the highest effectiveness regarding the proposed criteria with the least effect on sensory properties.

Keywords: bioactive compounds; herbal antioxidant; oil stability; natural preservative; color analysis

\section{Introduction}

Oxidation in food, especially in fats and oils, is a destructive process with adverse effects on their nutritional values and chemical composition (Henry and Heppell, 2002). It can also have undesirable effects on the color, taste, and texture of foods, while degrading the essential vitamins and fatty acids or creating toxic compounds (Stoilova et al., 2007; Wang et al., 2008). Antioxidants are natural or synthetic substances added to food products to prevent or delay the damage caused by oxygen (Sharififar et al., 2010). Although compounds such as tocopherols are naturally available in some oils, synthetic antioxidants with a phenolic structure are commonly used to prevent the oxidation of oils (Agregán et al., 2019; Mousavi Khaneghah et al., 2016).

Synthetic antioxidants, such as tertiary butyl hydroquinone (TBHQ), are inexpensive, easily accessible, and have high efficacy in inhibiting oxidation. TBHQ at $75 \mathrm{ppm}$ is used in the oil industry in many countries, including Iran. It affects the free radicals of lipids in oxidative chain 
reactions. Its phenolic group stabilizes free fatty radicals by using hydrogen and thus preventing the oxidation of fats (Wang et al., 2008).

However, some concerns have been raised regarding the mutagenicity and the role of synthetic antioxidants in the disruption of liver enzymes' activity as well as the development of diseases such as cancer and cardiovascular disease (Iqbal and Bhanger, 2007; Tavakoli et al., 2018). As a result, replacement of these compounds with natural antioxidants of plant origin has been considered. Antioxidant properties of plant extracts mainly depend on their phenolic compound content (Ahmed et al., 2019; Burt, 2004). In this regard, herbs and their derivatives (essential oils and extracts) with potent antioxidant properties are widely used to prevent the oxidative degradation of food (Hashemi et al., 2017; Tiwari et al., 2009).

"Kermanshahi Roghan," known as the "Roghan-eHeyvani," is an Iranian animal oil (IAO) and a yogurt by-product, like ghee and yayik butter commonly used in India and Turkey, respectively (Mostafaie et al., 2018). It is a traditional anhydrous milk fat product with a golden yellow color because of carotenoids. As an expensive dairy product, IAO is one of the most favorable oils consumed in many regions of Iran (Salarabadi et al., 2015). Produced from cow, sheep, or goat's milk, IAO is exported to many countries worldwide (Chalabi et al., 2018). The fatty acid composition of IAO ( $99 \%$ fat and $<0.2 \%$ moisture) is different from that of butter, as the lipids are extracted directly from milk. Therefore, it has lower long-chain fatty acids and cholesterol (Najafi et al., 2011).

Z. tenuior, Ferulago angulata (Chavill), and Bunium persicum (Black Caraway) belong to Lamiaceae, Apiaceae, and Chattrian, respectively. Z. tenuior (Bakhtiar et al., 2021) and F. angulata (Ghasemi Pirbalouti et al., 2016) are widely distributed in Iran. Also, B. persicum grows in areas with a Mediterranean climate such as Central and Western Asia (e.g., Iran) (Hassanzadazar et al., 2018). Due to their phenolic and flavonoid compounds, these plants have antioxidant and antibacterial activities, and gastrointestinal transit accelerating properties (Amiri and Joharchi, 2016; Dakah et al., 2019; Ehsani et al., 2016; Hazrati et al., 2019; Mahboubi, 2019).

Considering the increasing awareness among consumers regarding the harmfulness of synthetic additives in food, as well as studies on the use of herbal extracts to increase the shelf life of vegetative oils, the present study is designed to compare the oxidation of IAO treated with $Z$. tenuior, F. angulata, B. persicum, with that of synthetic antioxidant TBHQ.

\section{Materials and Methods}

\section{Extraction of essential oil}

Fresh IAO, free of any antioxidants, was purchased from a local market. The dried leaves of $Z$. tenuior, F. angulata, and $B$. persicum were obtained from the Iranian Institute of Medicinal Plants, Karaj, Iran. The essential oils were extracted from these leaves using a Clevenger-type apparatus (Biogenic, Brasilia, Brazil), and based on the steam distillation method of Gharibzahedi et al. (2015). The brief protocol is as follows:

One-hundred grams of the leaves were placed in the distillation flask, and the oil was extracted from the vegetal substrate at 5-, 15-, 30-, 60-, and 100-min intervals. In order to completely isolate the water from the essential oil, $0.5 \mathrm{~g}$ of sodium sulfate was added to the separation column each time. The extracted essential oils were stored at $4 \pm 1^{\circ} \mathrm{C}$ until experiment time. TBHQ and other chemicals were purchased from Merck Co. (Darmstadt, Germany).

\section{Preparation of the treatments}

Different concentrations of the essential oils and TBHQ were added to $100 \mathrm{~g}$ of IAO based on the values indicated in Table 1 and mixed using RH Basic 2 magnetic stirrer (Staufen, Staufen Germany). StaufenThe IAO samples were evaluated on days $0,7,14,21$, and 28 of storage. All tests were performed in three replications.

Table 1. Iranian animal oil treatments with incorporation of different essential oils and $T B H Q^{a}$.

\begin{tabular}{lcccc} 
Treatments & $\begin{array}{c}\text { Z. tenuior } \\
(\%)\end{array}$ & $\begin{array}{c}\text { F angulata } \\
(\%)\end{array}$ & $\begin{array}{c}\text { B. persicum } \\
(\%)\end{array}$ & $\begin{array}{c}\text { TBHQ } \\
(\mathbf{p p m})\end{array}$ \\
\hline T1 & 5 & - & - & - \\
T2 & 7 & - & - & - \\
T3 & 10 & - & - & - \\
T4 & - & 5 & - & - \\
T5 & - & 7 & - & - \\
T6 & - & 10 & - & - \\
T7 & - & - & 5 & - \\
T8 & - & - & 7 & - \\
T9 & - & - & 10 & - \\
T10 & - & - & - & 100 \\
T11 & - & - & - & 200 \\
T12 & - & - & - & 300 \\
\hline${ }^{b}$ & - &
\end{tabular}




\section{IAO analysis}

IAO with a peroxide value of less than 5 meq $\mathrm{O}^{2} / \mathrm{kg}$ was purchased from the Pegah Golpayegan Dairy Company (Golpayegan, Iran). It was kept at $4^{\circ} \mathrm{C}$ during the whole study, as recommended by the producer.

\section{Acid value}

The AV was defined as the amount (mg) of potassium hydroxide $(\mathrm{KOH})$ required to neutralize the free fatty acids in $1 \mathrm{~g}$ of IAO samples dissolved in a mixture of ethanol. The titration method was used to determine the AV according to ISO 660 (ISO, 2009) using the following equations:

$$
\text { Acid value }(\mathrm{mL} \mathrm{KOH} / \mathrm{g} \mathrm{IAO})=\frac{56.1 \times \mathrm{N} \times \mathrm{V}}{\mathrm{M}} \times 100(1)
$$

$\mathrm{N}$ : KOH normality; V: Consumed $\mathrm{KOH}$ volume $(\mathrm{mL}) ; \mathrm{M}$ : IAO weight $(\mathrm{g}) ; 56.1=\mathrm{KOH}$ molecular weight $(\mathrm{g} / \mathrm{mol})$.

\section{Peroxide value}

IAO was dissolved in a solution of isooctane and glacial acetic acid and then mixed with potassium iodide. Free iodine via peroxides was measured (ISO 3960, ISO, 2017) using iodometry in the presence of starch and sodium thiosulfate solution. PV was determined through sodium thiosulfate titration and was calculated using the following equation:

$$
\text { Peroxide Value }\left(\text { meq } \mathrm{O}^{2} / \mathrm{kg} \text { IAO }\right)=\frac{\mathrm{V} \times \mathrm{N}}{\mathrm{M}} \times 1000
$$

V: Consumed thiocyanate volume; N: Thiosulfate normality; M: IAO weight.

\section{Thiobarbituric acid value}

Thiobarbituric acid (TBA) value shows the amount of malondialdehyde (MDA) present in each $100 \mathrm{~g}$ of oil. MDA, commonly used as an oxidation marker, is one of the most abundant aldehydes generated during secondary lipid peroxidation in foods (Reitznerová et al., 2017). This method allows direct measurement of the TBA levels in fats and oils without the MDA's need for prior isolation. MDA reacts with TBA and forms a color complex with absorption maxima at a wavelength of $530 \mathrm{~nm}$ (AOCS, 2017).

$$
\mathrm{TBA}(\mathrm{mg} \text { MDA } / \mathrm{kg} \mathrm{IAO})=\frac{50 \times(\mathrm{A}-\mathrm{B})}{\mathrm{M}}
$$

A: Absorption of IAO sample; B: Absorption of TBA as the blank sample; $\mathrm{M}$ : IAO weight

\section{Oxidative stability}

The ability of the oil against oxidation is known as Os and is expressed as $h$. The test was performed based on the Rancimat technique using a Metrohm 743 Rancimat (FanAzma Gostar, Alborz, Iran) at $110^{\circ} \mathrm{C}$ and $20 \mathrm{l} / \mathrm{h}$ airflows
(ISO 6886, ISO, 2016). Oxidation resistance ends when a rapid increase is seen in the specific conductance due to the decomposition of the carboxylic acids resulting from lipid oxidation and their absorption in deionized water.

\section{Color analysis}

The color evaluation was performed using Hunter lab colorimeter (Hunter lab D25-DP9000, Germany) with black and white calibration plates. L* (lightness) from black (0) to 100 (white), a* (green-red), and b* (blue-yellow) was calculated from -120 to 120 (Guo et al., 2016).

\section{Sensory evaluation}

The sensory characteristics of the treatments such as odor, taste, rancidity, and overall acceptability of coded IAO samples during 28 days of storage were evaluated based on a 5-point hedonic scale from 1 (dislike very much) to 5 (like very much) (Mohammadi et al., 2011).

\section{Statistical analysis}

A randomized complete block design was applied. The data were analyzed by analysis of variance (ANOVA) using SAS 9 (SAS Institute Inc., Cary, NC, USA) followed by Duncan's multiple range test (Koushki et al., 2011). Values were reported as mean \pm standard deviation (SD) of six repetitions for each treatment. $P$ values $<0.05$ were considered statistically significant for all comparisons (Amiri-Rigi et al., 2011).

\section{Results and Discussion}

\section{AV, PV, TBA values and Os analysis of different IAO treatments}

AV value depends on the type and the amount of the applied essential oils. In other words, the difference in the $\mathrm{AV}$ is due to the difference in the antioxidant content of the active compounds as well as their ability to trap water. According to Figure 1A, there was a significant difference between the AV values of the controls (T10-T12) and that of the treatments containing essential oils $(P<$ $0.05)$. A decreasing trend was observed in AV values with increasing concentrations of essential oils. Treatments containing B. persicum and $Z$. tenuior were reported to have significantly lower AV values than those containing F. angulata. This is mainly because the high polyphenolic, flavonoid, and antioxidant content of treatments containing $B$. persicum deactivates free radicals derived from the environmental oxidation process (Hassanzadazar et al., 2018). AV indicates the progress of the oxidation process, and therefore its value decreases with the increasing flavonoid content of the oil. This is mainly because of the increased concentration of applied essential oils. 
(A)

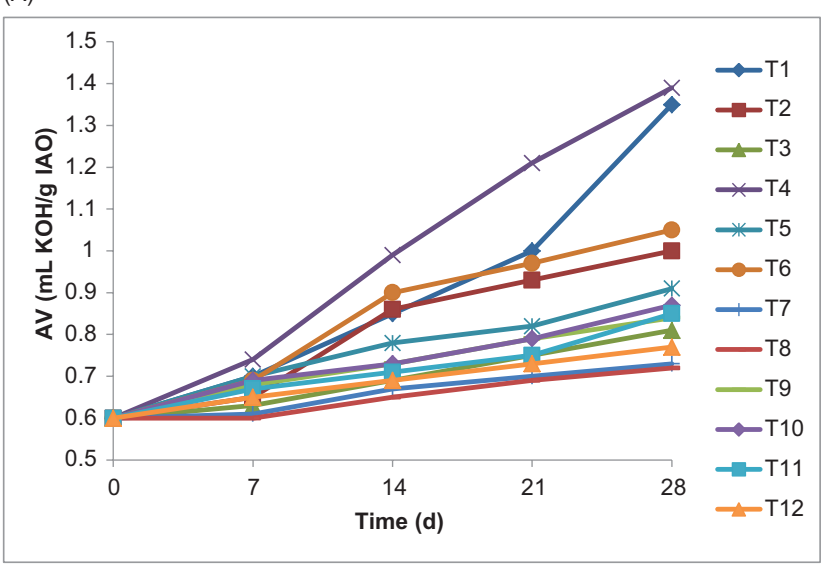

(C)

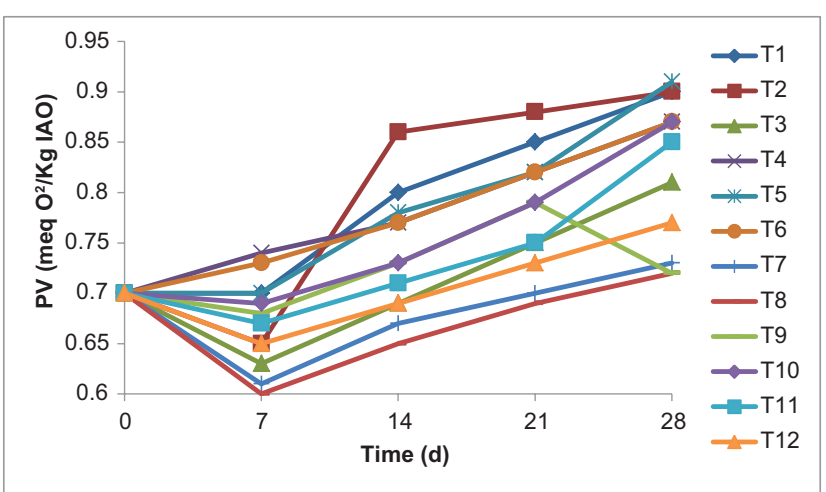

(B)

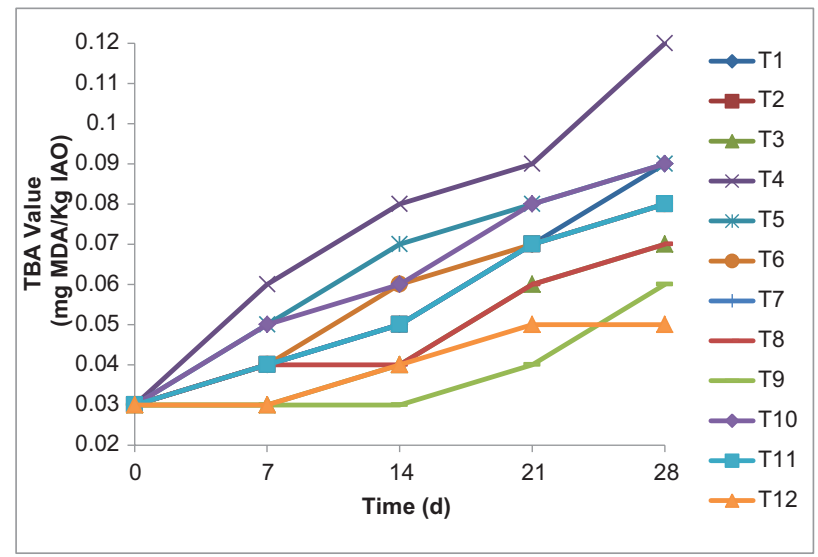

(D)

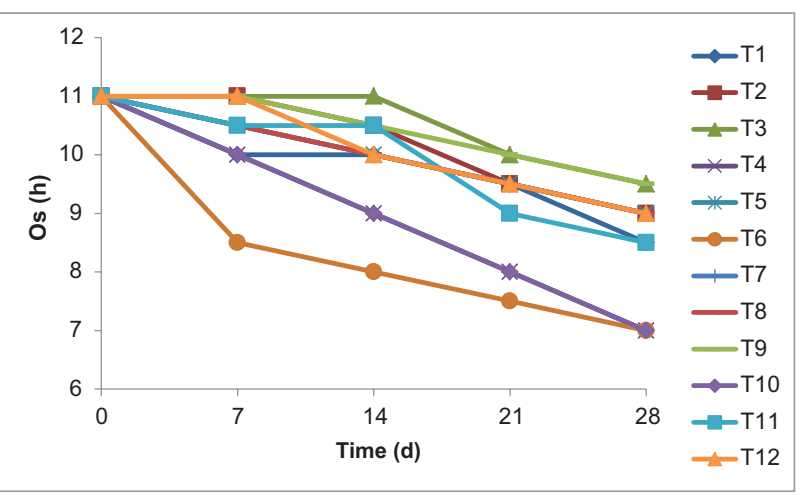

Figure 1. Acid value (AV) (A), peroxide value (PV) (B), Thiobarbituric acid (TBA) value (C), and oxidative stability (Os) (D) of Iranian animal oil treated with herbal essential oils during storage time.

Treatments (T1-T12) are described in Table 1.

There was an overall increase in the AV of IAO treatments with increased storage time that negatively affects the oil quality. This can be secondary to the increase of IAO's free fatty acid content during this time, either because of the hydrolysis of triglycerides or their formation as an end product of the oxidation process (Guo et al., 2016). Moreover, the increased exposure of oil to oxygen, light, and acidic compounds as the oxidation process progresses could also be responsible for the significant increase noted in the AV values. For instance, the increase noted in AV of IAO treatments containing B. persicum and Z. tenuior was lower than that of controls containing TBHQ. Treatments containing $10 \% \mathrm{~B}$. persicum and $Z$. tenuior had the lowest AV enhancement (28 days) $(P<0.05)$.

On the other hand, the AV of treatments containing F. angulata increased significantly during storage but was negatively correlated with the amount of $F$. angulata $(P<0.05)$. Compared with B. persicum and $Z$. tenuior, F. angulata is high in aromatic compounds but low in polyphenolic ones. In line with our findings, Najafi et al. (2011) showed similar results while studying the antioxidant effect of olive leaf and its extract on soybean oil stability (Najafi et al., 2011).
Unsaturated fatty acids such as oleic and linoleic acids with double bonds in their chemical structure are highly susceptible to oxidation-accelerating factors such as heat, light, oxygen, and lipoxygenase activity (Pradhananga and Manandhar, 2018). Hydroperoxides are the primary products of the oxidation reactions and are thus used to evaluate the oxidation reactions' progression (Alizadeh et al., 2016). IAO is very susceptible to oxidative corruption. According to Figure 1B, the use of essential oils changed the PV of the treated IAO significantly compared with the TBHQ-containing controls $(P<0.05)$. The treatments containing $B$. persicum had the lowest PV. This can be due to the presence of active compounds such as limonene and Trans-Carveol and limonene derivatives (Mohammadi et al., 2021). PV of all treatments increased with longer storage time, depending on the type and the amount of applied essential oil. Among the applied essential oils, F. angulata had the least effect on PV values. In other words, there was no significant difference between the PV of the F. angulata-treated IAO and the control containing $100 \mathrm{ppm}$ TBHQ. The least amount of change in PV values was reported in IAO containing $10 \%$ B. persicum after 28 days of storage $(P<0.05)$. Darughe et al. (2012) also found that the antioxidant compounds 
in B. persicum significantly inhibited any increase in PV values of the cake during storage (Darughe et al., 2012).

PV breaks down after reaching a certain level and the by-product compounds are formed (Pradhananga and Manandhar, 2018). For this reason, TBA value, alongside PV, was also investigated. According to Figure $1 \mathrm{C}$, there was a significant difference between the TBA values of different IAO treatments based on the type and the amount of applied essential oil $(P<0.05)$. TBA followed an increasing trend during the 28 days of storage. The treatment containing 5\% F. angulata had the highest TBA value, whereas treatments with $B$. persicum had the lowest increase in TBA value during storage $(P<0.05)$. This can be due to the increase in the latter's phenolic and limonene compounds that inhibited oxidation more effectively (Mohammadi et al., 2021). The high aromatic compound content of $F$. angulata, on the other hand, was not as effective in inhibiting the oxidation process. The increase noted in the TBA values of the IAO treatments indicates the formation of products such as aldehydes and ketones that have an adverse effect on the organoleptic properties of the oil (Serfert et al., 2010). In corroboration with our results, Hassanzadazar et al. (2018) also concluded that B. persicum could be used as a natural alternative to synthetic antioxidants based on the results of PV and TBA values of their investigation (Hassanzadazar et al., 2018).

Figure 1D illustrates a significant difference between the treatment's oxidation resistance time, and the controls $(P<0.05)$. Treatments containing 10\% of each essential oil had the highest Os compared with those with $5 \%$ and $7 \%$ of the corresponding essential oils. The Os rate in treatments containing B. persicum, regardless of their concentration, was higher than that of IAO samples treated with $F$. angulata and $Z$. tenuior. The lowest Os was reported in the IAO samples treated with $F$. angulata. Also, it was observed that the treatments with $B$. persicum had an Os equivalent to TBHQ. While increasing the storage time was associated with a significant decrease in the Os values, increasing the concentration of essential oils had the opposite effect $(P<0.05)$. The former could be secondary to the partial inactivation of phenolic compounds as well as an increase in the levels of secondary hydroperoxide compounds due to storage-related oxidation (Hashemi et al., 2016). Our results were also supported by the research on rosemary extract's antioxidant effects on soybean oil (Casarotti and Jorge, 2014).

\section{Color analysis of IAO treatments}

Color is one of the apparent qualitative properties of the food products with a substantial impact on their marketability. This points out the importance of evaluating
IAO's color indices treated with herbal essential oils as part of the quality control study. In this study, a* value did not change significantly due to the absence of red pigment and lycopene compounds in $Z$. tenuior, F. angulata, and $B$. persicum. $L^{*}$ and $b^{*}$ values of treated IAO samples during the 28 days of storage are shown in Figure 2 $(\mathrm{A}, \mathrm{B})$. Figure $2 \mathrm{~A}$ illustrates that IAO samples treated with $Z$. tenuior and F. angulata had lower $L^{*}$ values than the control and $B$. persicum-treated ones. In addition, treatment with higher concentrations of $F$. angulata and $Z$. tenuior resulted in a lower $L^{*}$ value than those containing $5 \%$ essential oils. Therefore, it could be concluded that the $L^{*}$ value is significantly but inversely correlated with the concentration of the essential oils $(P<0.05)$. This could be due to the significant but negative effects of the chlorophyll content and pigment content of herbal essential oils on the light reflection, and thus the $L^{*}$ value. Compared with $B$. persicum-treated IAO samples, the control IAO samples were not reported to have significantly different $L^{*}$ values.

The $L^{*}$ values of treatments decreased significantly with increasing storage time $(P<0.05)$. This reduction, which is believed to be secondary to oxidative and lipolytic corrosion, was not significant in IAO samples treated with

(A)

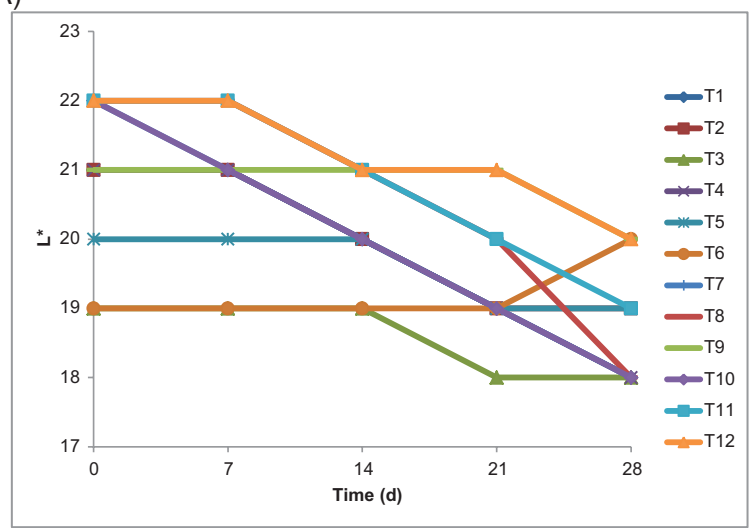

(B)

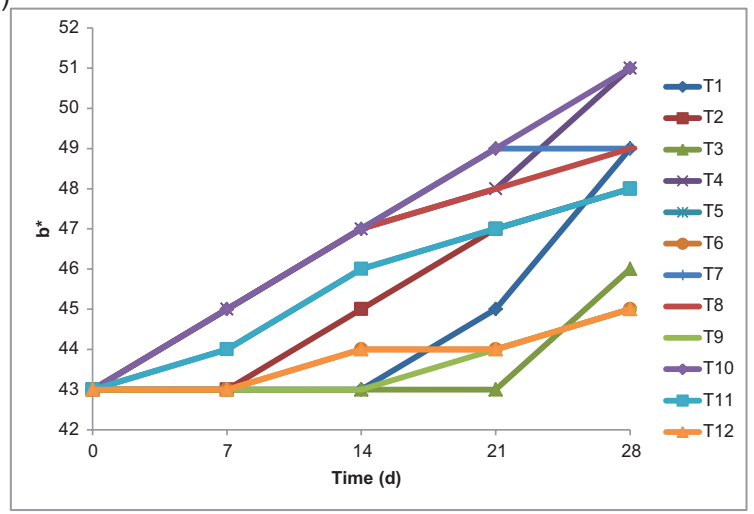

Figure 2. $\quad L^{*}$ value $(A)$ and $b^{*}$ value $(B)$ of Iranian animal oil treated with herbal essential oils during storage time. Treatments (T1-T12) are described in Table 1. 
essential oils at concentrations higher than $5 \%$. These findings are in line with that of Guo et al. (2016), who reported that the rosemary ethanol extract had a significant effect on the $L^{*}$ value of treated palm oil samples (Guo et al., 2016). They also reported that an increase in rosemary ethanol extract could decrease the $\mathrm{L}^{*}$ value of palm oil treatments. Similarly, Hozhabri et al. (2014) investigated the effect of fish oil and $Z$. tenuior on the quality and oxidation rate of the Mahabadi goat meat. They showed that the addition of $Z$. tenuior could significantly reduce $L^{* *}$ value (Hozhabri et al., 2014).

Figure 2B shows significant differences observed between the $\mathrm{b}^{*}$ values of various treatments $(P<0.05)$. The highest $\mathrm{b}^{*}$ value was observed in the treatment containing $5 \% F$. angulata essential oil, whereas the lowest values were found in those with $10 \%$ of B. persicum, F. angulata, and $Z$. tenuior $(P<0.05)$. An increasing trend in $\mathrm{b}^{*}$ values was reported in the treated IAO samples with increased storage time; the increase, however, was lower in the IAO samples containing $10 \%$ of essential oils and 300 ppm TBHQ. Similar results were reported in previous research into the antioxidant effects of rosemary extract on soybean oil (Casarotti and Jorge, 2014).

(A)

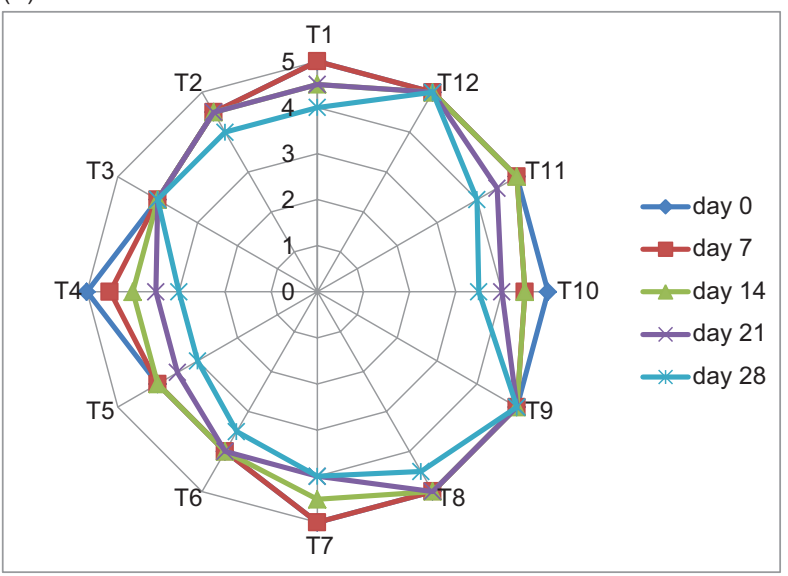

(C)
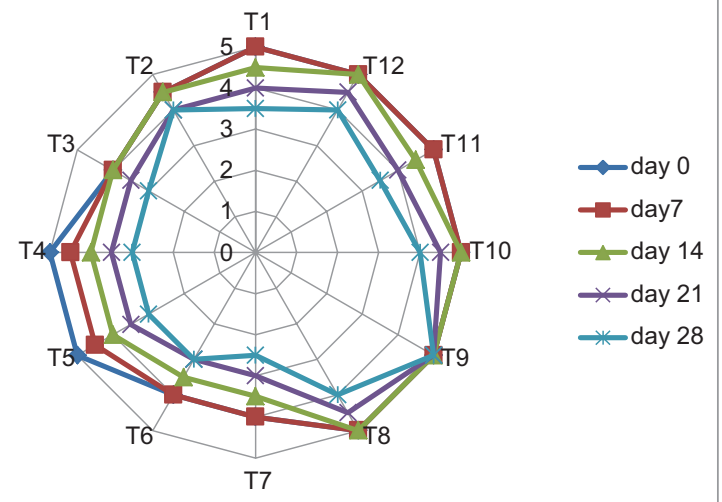

\section{Sensory evaluation of IAO treatments}

According to Figure 3A, a significant decrease in taste scores of treatments increased the essential oil concentration. One of the reasons for this may be the dominance of the plant's taste over IAO's special taste. Guo et al. (2016) also found that rosemary ethanolic extract in high amounts in palm oil caused a vegetable taste in palm oil. With increasing storage time, there was a decreasing trend in the taste scores of the treatments. Treatments containing higher than $5 \%$ essential oils had lower taste scores on day 0 , but they kept their scores steadily during storage time. Treatments with $F$. angulata and then $Z$. tenuior showed the lowest scores, but the treatments containing $B$. persicum had the same score as the control treatment with 300 ppm TBHQ. Even treatments with 200 and 100 ppm TBHQ had lower taste scores than those with $B$. persicum during storage until the end of day $28(P<0.05)$.

According to Figure 3B, increasing essential oil concentration led to a significant decrease in the odor scores in IAO treatments. Treatments with B. persicum had the least effect on the odor characteristic because the aromatic compounds in $Z$. tenuior and $F$. angulata are

(B)

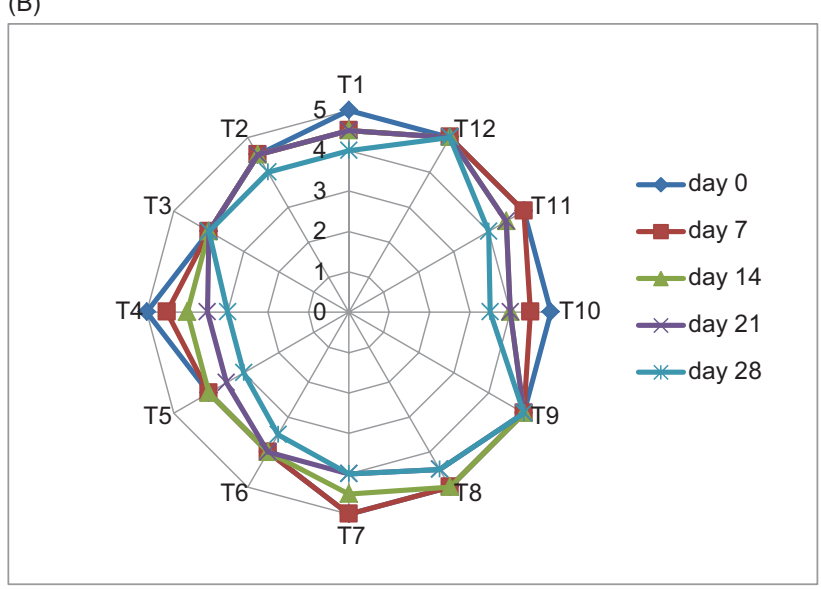

(D)

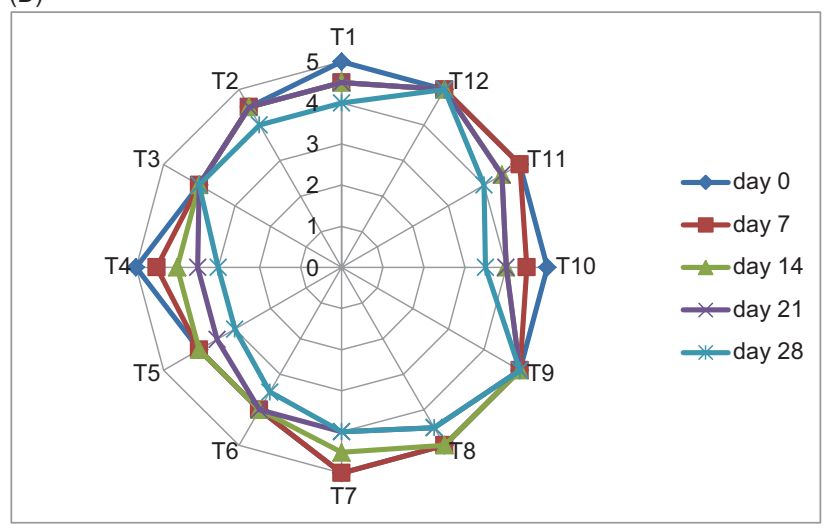

Figure 3. Taste scores (A), Odor scores (B), Rancidity scores (C), and Overall acceptability (D) of Iranian animal oil treated with herbal essential oils during storage time.

Treatments (T1-T12) are described in Table 1. 
higher than the B. persicum, which reduces IAO's odor. Also, during the storage period, the flavor and odor scores of all treatments significantly decreased $(P<0.05)$. This decrease in the treatments containing $F$. angulata was more than in the other treatments.

According to Figure 3C, minimum scores of rancidity belonged to treatments containing F. angulata and then to $Z$. tenuior; the highest scores belonged to treatments with $300 \mathrm{ppm}$ TBHQ and 10\% B. persicum. The results showed that the effect of $F$. angulata on the rancidity character of IAO was lower than the effect of B. persicum and $Z$. tenuior, which is due to the difference in the chemical content of these essential oils. All the essential oils extracted from three medicinal herbs have high amounts of bioactive compounds. Mohammadi reported that the main chemical constituents in Z. tenuior, F. angulata, and B. persicum essential oils were pulegone (12.77\%), ferulagon (14.97\%), and (+)-trans-carveol (57.70\%), respectively. However, higher total phenolic content, total flavonoid content, total carotenoid, and total chlorophyll in B. persicum essential oil were found compared to $Z$. tenuior and $F$. angulata essential oils (Mohammadi et al., 2021).

Also, increasing the essential oil concentration led to an increase in rancidity scores of treatments. During the storage period, the reduction of rancidity scores was lower in treatments with $10 \%$ essential oils. This can be due to the prevention of oxidation by essential oils during storage. Treatments containing $10 \%$ B. persicum had higher rancidity scores on the 28 th day in comparison to other treatments.

According to Figure 3D, treatments containing B. persicum and TBHQ had the highest overall acceptability among the other treatments. The overall acceptability of treatment containing 5\% F. angulata was significantly reduced because of the sensitivity of the $F$. angulata aroma and aromatic compounds of the F. angulata. Overall acceptability of all treatments decreased by increasing storage time, and increased by increasing essential oil content. Only the treatments containing 10\% B. persicum and $300 \mathrm{ppm}$ TBHQ maintained their overall acceptability until the end of the 28th day of storage time. Mehraban Sangatash et al. (2006) investigated the effect of Ziziphora Clinopodioides essential oil and extract on the activity of yogurt starter bacteria and found that the use of high concentration of essential oil reduced the final overall acceptability of yogurt treatments, which is consistent with the results of the present study.

\section{Conclusions}

It is concluded that increasing concentrations of $Z$. tenuior, B. persicum, and F. angulata are associated with a significant decrease in AV, PV, TBA value, $L^{*}$, and $b^{*}$ of the treated IAO. The addition of herbal antioxidants, regardless of their concentrations, also improved the Os of the treated IAO; their effects though started to decrease after 28 days of storage. Moreover, by increasing the essential oils' content, taste and odor of IAO decreased, while rancidity and overall acceptability were increased. The bioactive effects of the applied essential oils was found to be in the order B. persicum > $Z$. tenuior $>$ F. angulata. The addition of $10 \%$ B. persicum to the IAO was found to be an applicable and safe replacement for TBHQ. Our results are beneficial for developing strategies for producing edible oils and lipid-rich foods containing natural antioxidants with appropriate oxidative stability and pleasing sensory characterizations. In general, more study should be done to evaluate the antimicrobial effects of edible oils and emulsions enriched with the studied essential oils.

\section{Acknowledgments}

The authors would like to thank the National Nutrition and Food Technology Research Institute (Iran, Tehran) for providing the equipment required for this study.

\section{Conflict of Interest}

The authors of this manuscript wish to declare no conflict of interest associated with the submission and its content.

\section{References}

Ahmed, A.F., Attia, F.A.K, Liu, Z., Li, C., Wei, J. and Kang, W., 2019. Antioxidant activity and total phenolic content of essential oils and extracts of sweet basil (Ocimum basilicum L.) plants. Food Science and Human Wellness 8(3): 299-305. https://doi. org/10.1016/j.fshw.2019.07.004

Alizadeh, L., Nayebzadeh, K. and Mohammadi, A., 2016. A comparative study on the in vitro antioxidant activity of tocopherol and extracts from rosemary and Ferulago angulate on oil oxidation during deep frying of potato slices. Journal of Food Science and Technology 53(1): 611-620. https://doi.org/10.1007/ s13197-015-2062-2

AOCS, 2017. "American Oil Chemists' Society" 2-Thiobarbituric Acid Value. Direct Method. Official Method Cd 19-90. The American Oil Chemists' Society; Urbana, IL.

Amiri, M.S. and Joharchi, M.R., 2016. Ethnobotanical knowledge of Apiaceae family in Iran: a review. Avicenna Journal of Phytomedicine 6(6): 621-635. https://doi.org/10.22038/ajp.2016.6696

Amiri-Rigi, A., Mohammadifar, M.A., Emam-Djomeh, Z. and Mohammadi, M., 2011. Response surface optimisation of spray dryer operational parameters for low-phenylalanine skim milk 
powder. International Journal of Food Science \& Technology 46(9): 1830-1839. https://doi.org/10.1111/j.1365-2621.2011.02688.x

Agregán, R., Barba, F.J., Gavahian, M., Franco, D., Khaneghah, A.M., Carballo, J., et al. 2019. Fucus vesiculosus extracts as natural antioxidants for improvement of physicochemical properties and shelf life of pork patties formulated with oleogels. Journal of the Science of Food and Agriculture 99(10): 4561-4570. https:// doi.org/10.1002/jsfa.9694.

Bakhtiar, A., Khaghani, S., Ghasemi Pirbalouti, A., Gomarian, M. and Chavoshi, S., 2021. Essential oil variation among different populations of Ziziphora tenuior L. cultivated at semiarid climate. Journal of Essential Oil Research 1-9. https://doi.org/10. 1080/10412905.2021.1909666

Burt, S., 2004. Essential oils: their antibacterial properties and potential applications in foods - a review. International Journal of Food Microbiology 94(3): 223-253. https://doi.org/10.1016/j. ijfoodmicro.2004.03.022

Casarotti, S.N. and Jorge, N., 2014. Antioxidant activity of rosemary extract in soybean oil under thermoxidation. Journal of Food Processing and Preservation 38(1): 136-145. https://doi. org/10.1111/j.1745-4549.2012.00755.x

Chalabi, M., Bahrami, G. and Mostafaie, A., 2018. Kermanshahi roghan and yoghurt: comparison of fatty acid profiles and lipid qualities. International Journal of Dairy Technology 71(4): 893897. https://doi.org/10.1111/1471-0307.1254.1

Dakah, A., Zaid, S., Suleiman, M. and Dakka, M., 2019. Chemical components and antibacterial activities of essential oil of wild, in vitro and acclimatised plants of Ziziphora tenuior $\mathrm{L}$. International Food Research Journal 26(2): 723-730. Available from: http://www.ifrj.upm.edu.my/26\%20(02)\%202019/(39).pdf

Darughe, F., Barzegar, M. and Sahari, M.A., 2012. Antioxidant and antifungal activity of Coriander (Coriandrum sativum L.) essential oil in cake. International Food Research Journal 19(3): 1253-1260.

Ehsani, A., Hashemi, M., Naghibi, S.S., Mohammadi, S. and Khalili Sadaghiani, S., 2016. Properties of Bunium persicum essential oil and its application in Iranian white cheese against Listeria monocytogenes and Escherichia coli O157: H7. Journal of Food Safety 36(4): 563-570. https://doi.org/10.1111/jfs.12277

Gharibzahedi, S.M.T., Rostami, H. and Yousefi, S., 2015. Formulation design and physicochemical stability characterization of nanoemulsions of nettle (Urtica dioica) essential oil using a model-based methodology. Journal of Food Processing and Preservation 39(6): 2947-2958. https://doi.org/10.1111/jfpp.12546

Ghasemi Pirbalouti, A., Izadi, A., Malek Poor, F. and Hamedi, B., 2016. Chemical composition, antioxidant and antibacterial activities of essential oils from Ferulago angulata. Pharmaceutical Biology 54(11): 2515-2520. https://doi.org/10.3109/13880209.2 016.1162816

Guo, Q., Gao, S., Sun, Y., Gao, Y., Wang, X. and Zhang, Z., 2016. Antioxidant efficacy of rosemary ethanol extract in palm oil during frying and accelerated storage. Industrial Crops and Products. 94: 82-88. https://doi.org/10.1016/j. indcrop.2016.08.032

Hashemi, S.M.B., Brewer, M.S., Safari, J., Nowroozi, M., Sherahi, M.H.A., Sadeghi, B., et al. 2016. Antioxidant activity, reaction mechanisms, and kinetics of Matricaria recutita extract in commercial blended oil oxidation. International Journal of Food Properties 19(2): 257-271. https://doi.org/10.1080/10942912.2 015.1020438

Hashemi, S.M.B., Khaneghah, A.M. and de Souza Sant'Ana, A. eds., 2017. Essential oils in food processing: chemistry, safety and applications. John Wiley \& Sons. https://doi.org/10.1002/9781119149392

Hassanzadazar, H., Taami, B., Aminzare, M. and Daneshamooz, S., 2018. Bunium persicum (Boiss.) B. Fedtsch: an overview on phytochemistry, therapeutic uses and its application in the food industry. Journal of Applied Pharmaceutical Science 8(10): 150158. https://doi.org/10.7324/JAPS.2018.81019

Hazrati, S., Ebadi, M.T., Mollaei, S. and Khurizadeh, S., 2019. Evaluation of volatile and phenolic compounds, and antioxidant activity of different parts of Ferulago angulata (schlecht.) Boiss. Industrial Crops and Products 140: 111589. https://doi. org/10.1016/j.indcrop.2019.111589

Henry, C.J.K. and Heppell, N., 2002. Nutritional losses and gains during processing: future problems and issues. Proceedings of the Nutrition Society 61(1): 145-148. https://doi.org/10.1079/ PNS2001142

Hozhabri, A., Ganjkhanlou, M., Zali, A., Emami, A. and Akbari Afjani, A., 2014. Effect of fish oil and thyme essence on meat quality and meat oxidative stability of Mahabadi kids. Journal of Animal Science Research 23(4): 71-78. Available from: https:// animalscience.tabrizu.ac.ir/article_1041.html?lang=en

Iqbal, S. and Bhanger, M.I., 2007. Stabilization of sunflower oil by garlic extract during accelerated storage. Food Chemistry 100(1): 246-254. https://doi.org/10.1016/j.foodchem.2005.09.049

ISO, 2009. "International Organization for Standardization" Animal and vegetable fats and oils - Determination of acid value and acidity. ISO 660. Chemin de Blandonnet 8 CP 401 1214 Vernier, Geneva.

ISO. 2016. "International Organization for Standardization" Animal and vegetable fats and oils - Determination of oxidative stability (accelerated oxidation test). ISO 6886. Chemin de Blandonnet 8 CP 401 1214 Vernier, Geneva

ISO. 2017. "International Organization for Standardization" Animal and vegetable fats and oils - Determination of peroxide value Iodometric (visual) endpoint determination. ISO 3960. Chemin de Blandonnet 8 CP 4011214 Vernier, Geneva

Koushki, M., Khoshgozaran Abras, S., Mohammadi, M., Hadian, Z., Bagheri Poorfallah, N., Sharayei, P., et al. 2011. Physicochemical properties of mushrooms as affected by modified atmosphere packaging and $\mathrm{CaCl}_{2}$ dipping. African Journal of Agricultural Research 6(24): 5414-5421. Available from: http://www.academicjournals.org/AJAR

Mahboubi, M., 2019. Caraway as important medicinal plants in management of diseases. Natural Products and Bioprospecting 9(1): 1-11. https://doi.org/10.1007/s13659-018-0190-x

Mehraban Sangatash M., Karazhyan R., Hadad Khodaparast M.H., Habibi Najafi M.B., Beiraghi Toosi S., 2007. Effect of essential oil and extract of ziziphora clinopodioides on yoghurt starter culture activity. Iranian Journal of Food Science and Technology 3(4): 47-55. Available from: https://www.sid.ir/en/journal/ ViewPaper.aspx?id=279621 
Mohammadi, M., Khorshidian, N. and Gharibzahedi, S.M.T., 2021. The extended oxidative and sensory stability of traditional dairybased oil with steam-distilled essential oils extracted from the bioactive-rich leaves of Ziziphora tenuior, Ferulago angulata, and Bunium persicum. Journal of Food Quality 2021: 6613198. https://doi.org/10.1155/2021/6613198

Mohammadi, M., Koushki, M.R., Ahmadian, F.S. and Moslemy, M., 2011. The impact of home freezing on the sensory characteristics of ready-to-use leafy vegetables. Journal of the Science of Food and Agriculture 91(3): 519-522. https://doi.org/10.1002/ jsfa. 4215

Mostafaie, A., Gholamreza Bahrami, G. and Chalabi, M., 2018. Effect of fermentation temperature and different Streptococcus thermophilus to Lactobacillus bulgaricus ratios on Kermanshahi roghan and yoghurt fatty acid profiles. Journal of Dairy Research 85(4): 472-475. https://doi.org/10.1017/S0022029918000626

Mousavi Khaneghah, A., 2016. An overview on some of important sources of natural antioxidants. International food research journal 23(3): 928-933.

Najafi, T., Eghtesadi, S., Rezaie, M. and Daneshvar, K., 2011. The effect of Kermanshahi animal oil on serum lipids profile in healthy men. Journal of Kermanshah University of Medical Sciences 14(4): e79442. Available from: https://www.sid.ir/en/ journal/ViewPaper.aspx?id=189449

Pradhananga, M. and Manandhar, P., 2018. Preservative effects of some selected spice oleoresins to stabilize the sunflower oil in comparison to tertiary butylhydroquinone. Food Science \& Nutrition 6(2): 302-306. https://doi.org/10.1002/fsn3.555

Reitznerová, A., Uleková, M., Nagy, J., Marcinčák, S., Semjon, B., Čertík, M., et al. 2017. Lipid peroxidation process in meat and meat products: a comparison study of malondialdehyde determination between modified 2-thiobarbituric acid spectrophotometric method and reverse-phase high-performance liquid chromatography. Molecules 22(11): 1988. https://doi. org/10.3390/molecules22111988
Salarabadi, A., Arbabi Bidgoli, S. and Madani, S.H., 2015. Roles of Kermanshahi oil, animal fat, dietary and non-dietary vitamin D and other nutrients in increased risk of premenopausal breast cancer: a case control study in Kermanshah, Iran. Asian Pacific Journal of Cancer Prevention 16(17): 7473-7478. https://doi. org/10.7314/apjcp.2015.16.17.7473

Serfert, Y., Drusch, S. and Schwarz, K., 2010. Sensory odour profiling and lipid oxidation status of fish oil and microencapsulated fish oil. Food Chemistry 123(4): 968-975. https://doi. org/10.1016/j.foodchem.2010.05.047

Sharififar, F., Yassa, N. and Mozaffarian, V., 2010. Bioactivity of major components from the seeds of Bunium persicum (Boiss.) Fedtch. Pakistan Journal of Pharmaceutical Sciences 23(3): 300304. https://pubmed.ncbi.nlm.nih.gov/20566444/

Stoilova, I., Koastanov, A., Stoyanova, A., Denev, P. and Gargova, S., 2007. Antioxidant activity of a ginger extract (Zingiber officinale). Food Chemistry 102(3): 764-770. https://doi. org/10.1016/j.foodchem.2006.06.023

Tavakoli, J., Hashemi, S.M.B., Mousavi Khaneghah, A., Barba, F.J., Amorati, R., Esmaeilzadeh Kenari, R., et al. 2018. Improving the frying performance and oxidative stability of refined soybean oil by tocotrienol-rich unsaponifiable matters of Kolkhoung (Pistacia khinjuk) hull oil. Journal of the American Oil Chemists' Society 95(5): 619-628. https://doi.org/10.1002/aocs.12065

Tiwari, B.K., Valdramidi, V.P., O’Donnell, C.P., Muthukumarappan, K., Bourke, P. and Cullen, P.J., 2009. Application of natural antimicrobials for food preservation. Journal of Agricultural and Food Chemistry 57(14): 5987-6000. https://doi.org/10.1021/ jf900668n

Wang, J., Sun, B., Cao, Y., Tian, Y. and Li, X., 2008. Optimisation of ultrasound-assisted extraction of phenolic compounds from wheat bran. Food Chemistry 106(2): 804-810. https://doi. org/10.1016/j.foodchem.2007.06.062 